\title{
Agile as an enabler towards innovation-based organisational transformations
}

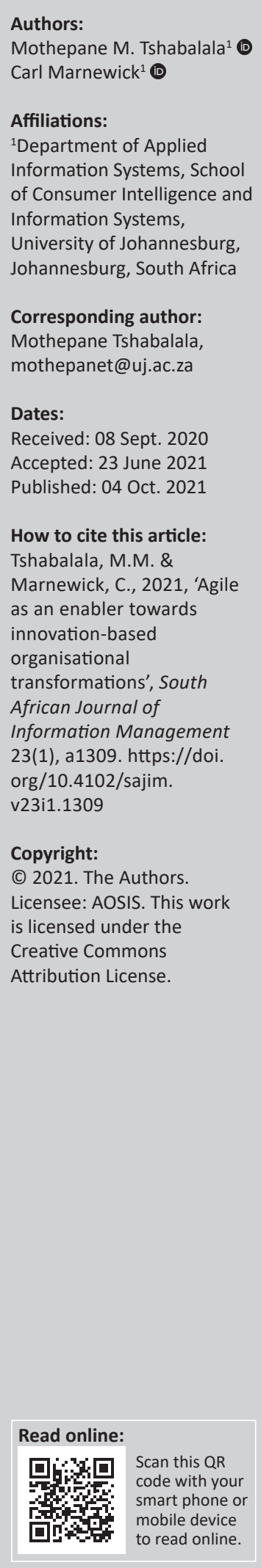

Background: Organisations must respond quickly and consistently to ongoing global shifts. This streak separates remaining competitive from losing market share. Globalisation has accounted for the majority of this transformation, which has been reinforced by rapid digital transformation. Industry experts and researchers are continually studying effective remedies to this worldwide transition as part of their response to this drive. This is required because the world is changing unavoidably, and effective responses to the change should be investigated.

Objectives: To study the relationship between Agile and innovation, and how this relationship might facilitate organisations' reaction to global changes, in response to the battle of how to adapt to global transformations successfully.

Method: A systematic literature review analysing 1645 peer-reviewed journals through the use of social network analysis.

Results: The terms 'Agile,' 'digital transformation', 'design thinking', 'agility', 'innovation management', 'lean', 'Industry 4.0', 'Agile development' and 'digital innovation' have the strongest links to 'innovation'. This demonstrates how innovation is reliant on Agile and its characteristics. Furthermore, the computed data clusters from the analysed dataset led to five propositions: (1) Agility sustains innovation strategies (P1). (2) Collaborating Agile methodology with digital innovation leads to competitive advantage (P2). (3) Agile development accelerates or facilitates new business models, such as Industry 4.0 (P3). (4) Design thinking creates value in innovation management or development of new product (P4). Lastly, (5) the concept or theory of lean Agile management (P5).

Conclusion: The correlation between Agile and innovation is critical for effective responses to global digital transformations that are ongoing.

Keywords: Agile; innovation; strategy; business information systems; digital transformation.

\section{Introduction}

Over the past decade, organisations have taken drastic steps to bring them closer to the technology efficiency required to adapt to the constantly changing technology demand. The most attempted step is the status of complete digital transformation (Tokody 2018). In the last decade, business process technology has been one of the engines and enablers of organisational transformation. A business process basically reflects a particular way to conduct and organise business operations. However, to enable effective business process technology, Rix et al. (2016) suggested that the overall mindset within organisations is the key. Adopting a mindset that advocates for change adaptability and constant satisfaction of market demands could, therefore, be one solution to this.

The Agile revolution is rapidly transforming the nature of the business world and the nature of work itself (Balashova \& Gromova 2017). The Agile Manifesto first introduced Agile as a methodology for managing technology projects. However, this soon transformed into an entire mindset of doing things differently within organisations. Agile represents a set of attitudes, standards and principles that complement an Agile working environment (Fuchs \& Hess 2018). Agile principles include attributes such as collaboration, constant improvement and learning cycles, focus on value delivery, pride in ownership and, most importantly, the ability to adapt to ever-changing business world demands (O'Leary, Cota \& Otis 2017). It is through Agile, together with its principles, that organisations have effectively transitioned successfully through the changing business models brought about by globalisation and, most recently, digitalisation, and this has been facilitated mostly through innovative efforts within organisations (Morris 2016). 
The question that remains now is whether there is any clear indication of this interdependency between Agile and innovation, or even vice versa - an indication that makes organisations understand why and where the interdependency exists and, most importantly, how they can conceptualise this entire concept within their operations. This study, therefore, aimed to map the influence of Agile adoption on organisations' ability to manage innovation effectively. The three objectives of this study were as follows:

- determine if there is an existing relationship between Agile and innovation

- outline the nature of this relationship and how it is manifested across various concepts (topics) in organisations

- develop propositions on how organisations can benefit from effective combination of Agile and innovation.

Previous research has been conducted on various ways and techniques that organisations can adopt to respond to current global transformation. However, no research has directly linked the adoption of Agile and effective innovation management to facilitate organisations' ability to respond to global transformation.

For this study, a systematic literature review (SLR) with a citation search was conducted as a data collection technique. An in-depth social network analysis (SNA) was then conducted. Two techniques of SNA were implemented: a keyword co-occurrence analysis and cluster analysis. The results from the analysis are discussed and mapped to practical implementation that organisations can engage with.

\section{Literature review Overview}

Globalisation has placed a huge obligation on organisations to imagine business even far beyond their physical frontiers (Mbelli \& Hira 2016). This has enforced a critical drive for organisations to change to newer business models as a way to survive this new way of business and, most importantly, be adequately competitive, effective and efficient to realise profits (Morris 2016). Information and communication technology (ICT) has played a significant role in this reality of globalisation and therefore organisations have had to make certain that their ICT is efficient and effective ( $\mathrm{O}^{\prime}$ Leary et al. 2017). Successful delivery of ICT systems in recent years has promoted the world to become the giant online space we see today. Effective management of ICT development projects has become the cornerstone for successful delivery (Morris 2016).

To respond to the need for effective and efficient ICT systems and improved success rate of ICT development projects, organisations have transitioned to Agile (Fuchs \& Hess 2018). Agile as an approach to ICT project development and agility as an entire mindset give organisations the flexibility to meet the continually changing market conditions and customer needs (Balashova \& Gromova 2017). This approach to business has also situated organisations in a state of high technological competitiveness and readiness that have kindled the start of an entirely new digital transformation and new innovative business models (Kohnová, Papula \& Salajová 2019). The pressure to come up with innovative ways to compete in this new era has fostered the need for effective organisational innovation management strategies, which empower organisations to adopt systematic promotion of innovations (Krstić, Skorup \& Lapčević 2018). The objective of organisations has transitioned from being only about meeting the organisational strategic goals to investing in processes that facilitate the continuous establishment of innovative ways to meet those goals (Agostini \& Filippini 2019). There is, therefore, a crucial need for an effective innovation strategy and management of this strategy within organisations. This article reviews the relationship between Agile and innovation within organisations, and how this relationship can be managed to facilitate organisational transformation.

\section{Agile}

Agile was first introduced as an iterative approach for software development (Beck \& Beedle 2001). Its aim was to help software development teams deliver value constantly and faster to their clients, instead of implementing the entire project at once. However, these excellent attributes were quickly adopted beyond the technology discipline (Khalil \& Kotaiah 2018). Agile soon emerged as a huge global movement that was driven by an enlightenment that Agile principles were the only possible way organisations could cope with today's unsettled customer-driven demands and the changing marketplace (Mbelli \& Hira 2016). Agile facilitates organisations' ability to excel in continuous change in handling. It permits businesses to flourish in this world that is increasingly volatile, uncertain, complex and ambiguous (Balashova \& Gromova 2017).

\section{Agile as an enabler of transformation}

Rigby, Sutherland and Takeuchi (2016) stated that one of the major reasons for adopting Agile should be to improve innovation across all functions of the business. They further explained that Agile should not be perceived only as a flexible, iterative prototyping system, but as a welldeveloped, well-rounded system created to overcome various common obstacles to successful innovation. The study by Thrassou, Vrontis and Bresciani (2018) on Agile and innovation revealed that Agile is indeed an enabler of innovative transformations within organisations, and Agile's value has been realised in various organisational functions such as operations, marketing and corporate strategy (Rigby et al. 2016). The current technology competitiveness has forced organisations to be innovative in order to survive.

The continuous technological transformation has forced organisations to develop new business models that respond to this transformation effectively. Krstić et al. (2018) suggested that organisations' response to this transformation should be 
the adoption of Agile and its principles. They stated that Agile facilitates innovation efforts that enable organisations to be flexible and adaptive during the initial introduction stage of projects, as well as in integrating design with development, therefore making innovation processes noticeably faster. Morris (2016) maintained that Agile as an approach makes it possible for organisations to promote and elevate innovation, by ensuring possible and smooth implementation of systems that enable an organisation's technological competitiveness. In summary, Agile is an enabler of organisational transformation, and the following features of Agile make this possible: (1) Agile has inherent flexibility and an adaptable nature, (2) Agile advocates for speedy results, and (3) Agile is an all-inclusive process that supports individual interactions and team collaborations (Wagner, Herrmann \& Thiede 2017).

\section{Innovation}

At its foundation, innovation refers to a systematic generation and promotion of new ideas, and the implementation of these ideas into new products, processes or services within organisations (Kogabayev \& Maziliauskas 2017). According to Nambisan et al. (2017), innovation leads to a dynamic transformation that accelerates growth towards the innovative business enterprise and national economy. Şimşit, Vayvay and Öztürk (2015) suggested that effective management of innovation within organisations is represented by the systematic promotion of innovations that include managing the tasks of planning, organisation, management as well as control of innovation efforts within organisations. Innovation is not a one-time initiative, but an ongoing, cumulative process consisting of boundless counts of organisational decision-making processes, extending from the initial phase of new idea generation to its implementation phase (Kogabayev \& Maziliauskas 2017).

From an economic point of view, a growth in an organisation's innovation graph means increasing achievement in the organisation's ability to address various problems and meet set objectives (Nambisan et al. 2017). The main objective for organisations has not only been to meet the strategic goals, but also to determine innovative ways to meet those goals (Yun et al. 2019). One principal strategy to sustain business development in the current global environment is using innovative technology platforms (Nambisan et al. 2017). The processes of managing innovation in organisations are depicted (Figure 1):

- Innovation management strategy: This incorporates all measures taken by an organisation to promote and implement innovation efforts. The focus of innovation management is the integration of both new innovative efforts as well as the benefits of that innovation. This leads to continuous development of new, value-adding products, business models as well as processes.

- Systematic promotion of innovations: Effective innovation management relies on endless, methodical processes that are continuously implemented towards the support of innovation efforts within organisations. The

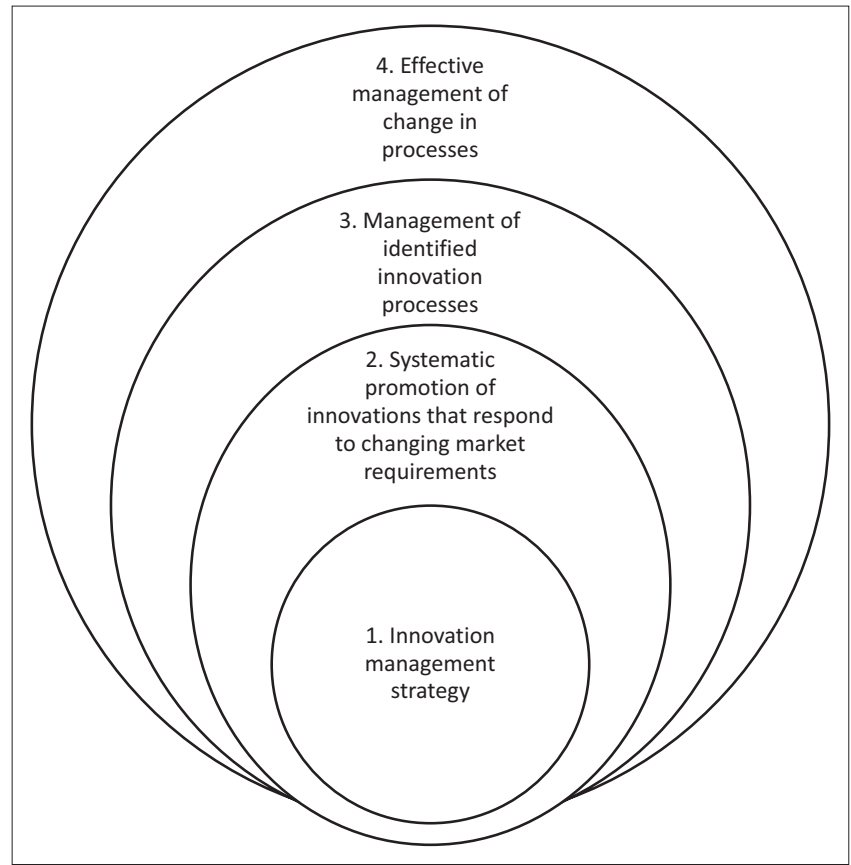

Source: Horth, D. \& Buchner, D., 2014, Innovation leadership: How to use innovation to lead effectively, work collaboratively and drive results, p. 20, Center for Creative Leadership, Greensboro.

FIGURE 1: Processes of innovation management.

efficiency of the process of innovation management depends primarily on organised, structured initiatives towards innovation within organisations.

- Management of identified innovation processes: This stage involves the administration, supervision and controlling of the innovation processes that have been implemented within organisations.

- Effective management of change in processes: Successful and value-added management of innovation processes and efforts within organisations requires swift adaptability and response to change. This ensures ongoing effective management of innovation by organisations.

The literature suggests that effective innovation transformation within organisations is enabled by the need for constant change and adaptability (Bahron 2018). On the other hand, the literature states that Agile as a mindset is a key to effective change management and adaptability (Mergel 2016). If Agile is a driver of transformation and innovative efforts are what is required to sustain organisational transformation, then it is critical to investigate the link between Agile and sustainable innovation efforts to facilitate organisational digital transformation. The literature review outcomes on innovation and Agile are illustrated (Figure 2).

\section{Methodology Data collection}

For this study, a SLR methodology was adopted. Systematic literature review focusses on a review of numerous studies in the same area of study (Siddaway 2014). An advantage of this methodology is the ability to synthesise available research evidence representative of a specific topic. Agile is applied 


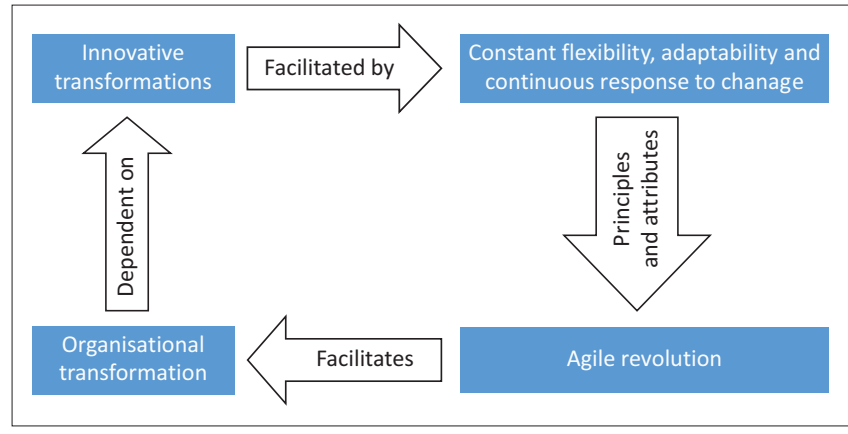

FIGURE 2: Literature review summary.

across multiple disciplines. It was, therefore, necessary for only available research evidence applicable to the particular topic explored by the study to be reviewed. The process set out below was followed:

- A list of fundamental search terms applicable to the study was created. These key terms were derived from the study research topic. The keywords were 'Agile AND innovation' OR 'Agile transformation' OR 'Agile AND innovation management'.

- The sources of literature to be used for the primary searches were identified. Scopus online database was selected to search for the relevant research articles. Scopus is the leading abstract and citation database with peerreviewed literature. From this process, the study dataset was created (IOWA State University Library 2018).

- Scopus online database provided many merits specifically necessary for the required datasets of this study. Firstly, an interdisciplinary field coverage feature was beneficial to obtain a broader view and definition of the focus topics (IOWA State University Library 2018), which are 'the fourth industrial revolution' and 'agile'. Secondly, Scopus offers the largest abstract and citation database of peer-peer reviewed literature; this is inclusive of scientific journals, conference proceedings and books (Elsevier 2019). Scopus provides smart tools that track, examine, analyse and visualise research. Lastly, Scopus features approximately 36377 titles from nearly 11678 publishers, and about 34346 are peerreviewed journals within top-level subject fields (Elsevier 2019).

- The keyword search on Scopus was conducted on the 'Title, abstract and keywords' selections.

- A systematic, precise citation search was conducted using the identified keywords on the Scopus online library, which resulted in a dataset of 3629 articles.

- Inclusion and exclusion criteria were further applied to the dataset:

- The dataset was restricted to articles that were written only in English. This is because English is the mode of business communication. This resulted in 3540 articles.

- Articles were restricted to those that were published between 2015 and 2020. This was to ensure that the study would work on recent, available data. This reduced the articles to 1467 .
- Articles had to fall into the subject areas of computer science, business and management, economics as well as engineering. This criterion was applied to ensure that the results included only articles from possible subject areas that recognise Agile and its status as an approach or mindset to doing things. This reduced the articles to 842 , to be used as the dataset for the review. The dataset was exported as an RIS file.

- When extracting the dataset, the selections made included the inclusion of the citation details as well as the abstract and keywords.

\section{Data analysis}

For the analysis process, SNA was conducted using a combination of keyword co-occurrences and cluster analysis techniques. This process evaluates and analyses the interdependent keywords' relationships within the dataset. From these findings, the researcher can interpret and deduce meaning behind them.

\section{Social network analysis}

Social network analysis is a technique used to conduct research that employs the measuring and analysing of the structural properties of connections or networks of interdependent node relationships such as entities, people, organisations or things within the network (Serrat 2017). According to De Brún and McAuliffe (2018), the focus of SNA is typically on the 'links and relations' made amongst the network participants, showing how and where they interact and communicate. The focus of this study was on the interdependence of keywords within the network, based on the keywords 'Agile AND innovation' OR 'Agile transformation' OR 'Agile AND adoption'.

Visualizing Scientific Landscape (VOS) viewer software was used to create the networks for the SNA. VOSviewer is a scientometric and bibliometric software analysis tool for creating maps based on network data and for visualising and exploring these maps (Van Eck \& Waltman 2010). VOSviewer was used to conduct a co-occurrence analysis of terms and keywords. This analysis also yielded the link strength of each keyword within the network. VOSviewer's terms and keywords co-occurrence analysis provides an evaluation and analysis of the keywords based on collected authors' studies which form a dataset for the analysis tool (Van Eck \& Waltman 2010). Two keywords occurring in different articles indicate an existing connection between the topics represented by these studies.

Additionally, cluster analysis was performed, which uses keywords with distinctive characteristics such as the clustering object to find popular words or terms that have existed within the specific research field for many years. Through this, the distribution of existing keywords and terms can easily be depicted.

\section{The social network analysis process conducted}

- Step 1: The Research Information Systems (RIS) file was extracted from the Scopus online library and imported to the VOSviewer scientometric and bibliometric software analysis tool. 
- Step 2: The keyword co-occurrence option was selected to perform the keyword concurrence analysis.

- Step 3: A threshold of five or more keyword cooccurrences was selected. According to De Brún and McAuliffe (2018), a threshold of more than three keyword co-occurrences signifies the profound suitability and applicability of the specific keyword to the topic being investigated.

- Step 4: The output keywords table was examined to remove any keywords that were found to be unrelated to the study.

- Step 5: Lastly, the computation was run on the dataset.

The SNA keyword co-occurrence and cluster visualisation network results are illustrated (Figure 3 and Figure 4).

From Figure 3, which illustrates the study keyword concurrence network, the following analyses can be deduced.

Innovation and agile are the largely represented keywords, which are expected because they are the search words used. However, from the network based on the combination of these two keywords, the study can deduce that there are keywords that share some close and strong relation with these two key concepts, such as the concepts of design thinking, agility, project management, digital transformation and industry 4.0. The concepts with strong relation to the combination of these two keywords are identified by the size of the circular ball shapes representing the keywords. From these findings, we can now determine concepts that are agile based, based on the literature review above, such as project management, agility and digital transformation to determine that there is a relation between Agile and innovation, and it is exhibited through these keywords provided on the keyword co-occurrence analysis network demonstrated in Figure 3.

\section{Study findings Relationship between Agile and innovation}

To identify the relationship between Agile and innovation, the results of the link strength and co-occurrence analysis were derived. From this analysis, keywords were identified that occurred across different articles, which indicate an existing connection and interdependency between the keywords, and topics represented by the studies being reviewed. The top 20 keywords with the highest occurrences are listed (Table 1).

The keyword innovation has the highest co-occurrence count. In addition, looking at Figure 3, the boldest keyword is innovation, which indicates that it is the keyword most represented across the reviewed studies. The subsequent keywords mostly represented within the reviewed studies which interlink with innovation are Agile, digital transformation, design thinking, agility, innovation

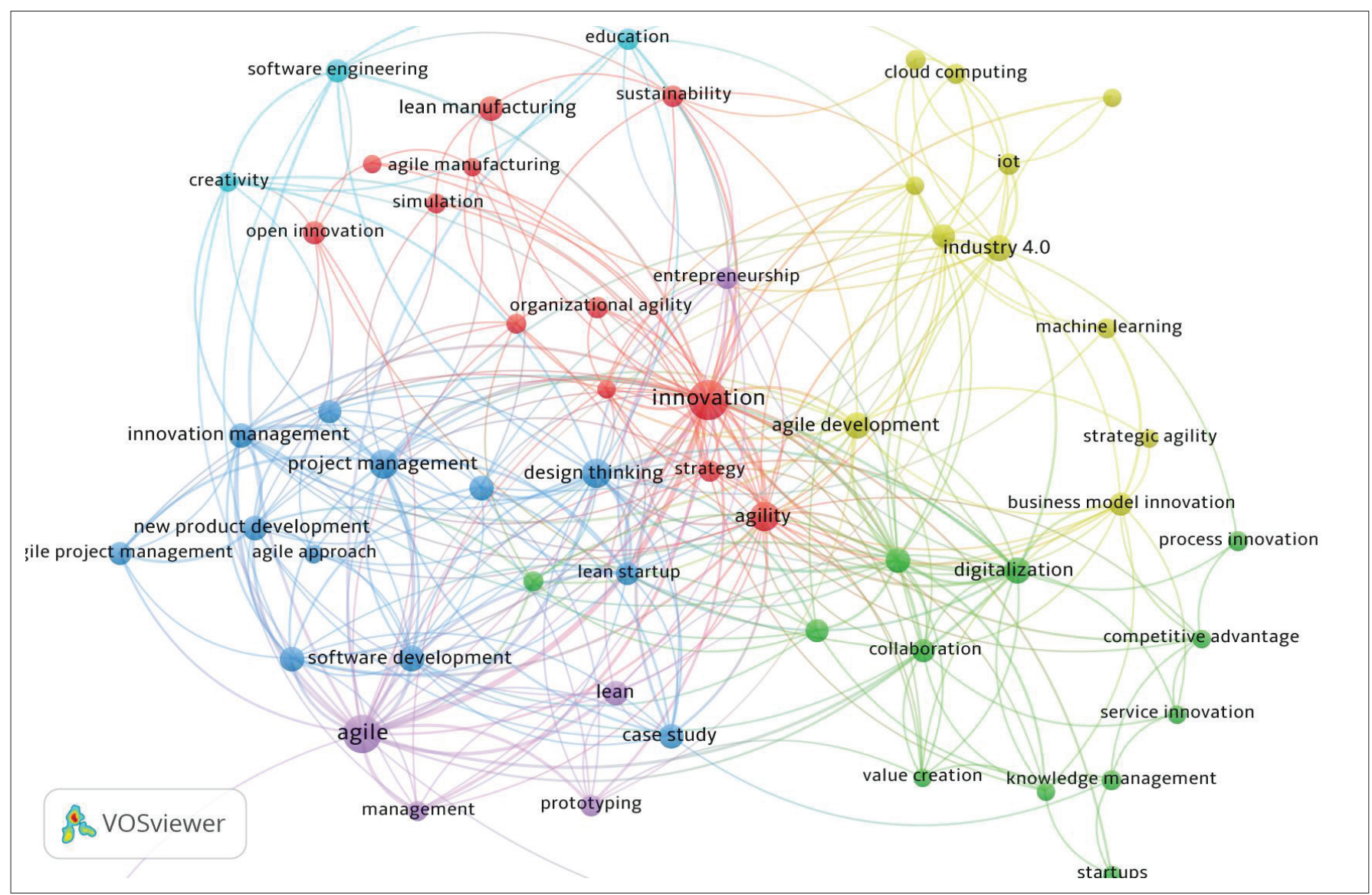

FIGURE 3: Keyword co-occurrence network. 


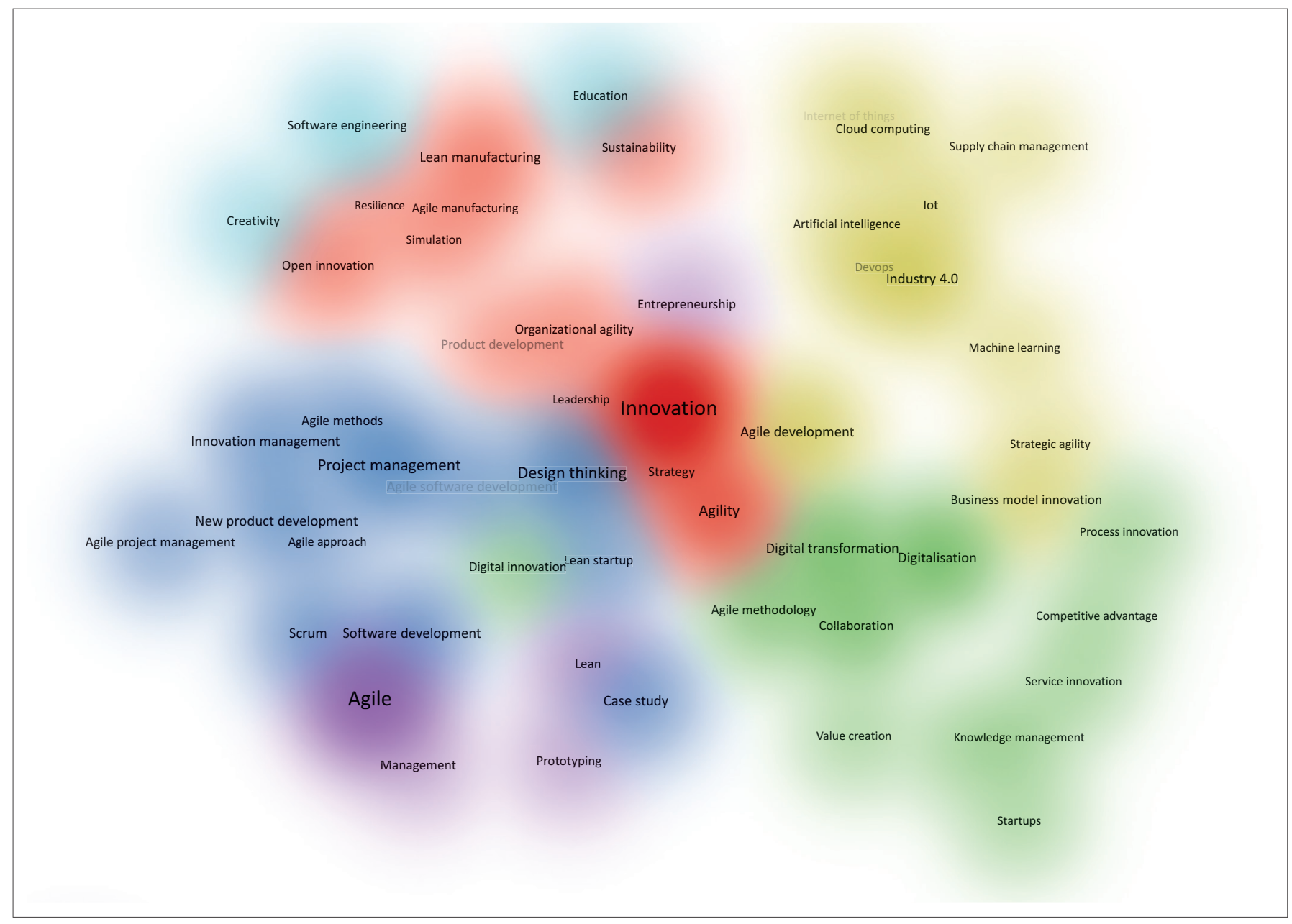

FIGURE 4: Keyword cluster visualisation network.

management, lean, Industry 4.0, Agile dev, project management and digital innovation.

Moreover, Figure 3 illustrates the link strength between keywords, which indicates an established link and interdependency between the keywords. The link strength is illustrated by arrows across keywords. The top 20 keywords with the highest link strength are listed (Table 2). The top 10 keywords with the highest link to innovation are agility, innovation, lean, digital transformation, Agile, design thinking, Industry 4.0, change adaptability, new product development and business model innovation.

\section{The nature of the relationship}

To determine the nature of the relationship between Agile and innovation, the results of the cluster analysis were derived (Figure 4). The clustering analysis facilitated the profiling of the 'Agile and innovation' dataset, which assisted in deducing the meaning behind the data. Five major clusters were identified from the density visualisation network in Figure 4, and propositions for each cluster could be deduced. Propositions were selected because the nature of the empirical aspect of this research study was exploratory.
TABLE 1: Top 20 co-occurring keywords.

\begin{tabular}{lc}
\hline Keyword & Co-occurrence count (highest to lowest) \\
\hline Innovation & 118 \\
Agile & 105 \\
Digital transformation & 67 \\
Design thinking & 53 \\
Agility & 45 \\
Innovation management & 43 \\
Lean & 32 \\
Industry 4.0 & 31 \\
Agile development & 26 \\
Project management & 26 \\
Digital innovation & 23 \\
Strategy & 23 \\
Open innovation & 21 \\
Lean & 19 \\
Entrepreneurship & 18 \\
Management & 18 \\
Collaboration & 17 \\
Effectiveness & 15 \\
Creativity & 15 \\
Leadership & 14 \\
\hline &
\end{tabular}

These propositions are derived based on the keywords within a cluster. The importance of the keyword on the proposition is based on the strength of that keyword in the cluster. P1 below as proposition one, is based on the fact that innovation as the keyword most represented (highest connection 
TABLE 2: Top 20 keywords with high link strength.

\begin{tabular}{lc}
\hline Keyword & Link strength (highest to lowest) \\
\hline Agility & 84 \\
Innovation & 66 \\
Lean & 38 \\
Digital transformation & 33 \\
Agile & 27 \\
Design thinking & 25 \\
Industry 4.0 & 16 \\
Change adaptability & 14 \\
New product dev & 14 \\
Business model innovation & 18 \\
Scrum & 15 \\
Collaboration & 12 \\
Acceleration & 11 \\
Open innovation & 11 \\
Leadership & 10 \\
Strategy & 10 \\
Organisation agility & 12 \\
Facilitation & 11 \\
Entrepreneurship & 7 \\
\hline &
\end{tabular}

strength) needs agility (as the second most represented keyword) and lastly, strategy as the least represented keyword within the cluster. Hence, the researcher proposition that agility is needed as a strategy to sustain (sustainability as another keyword in Cluster 1) innovation. The results are illustrated (Table 3): Keywords depicted in the propositions will be marked in bold for easy understanding.

\section{Discussion}

Innovation is one aspect organisations engage in to curb and respond to the constant demands brought by technology transformations and globalisation (Caruso 2018). The need to establish ways to respond these critical constant demands is growing significantly (Mbelli \& Hira 2016). Researchers and industry experts are on a constant journey of identifying and investigating effective ways organisations can employ to respond to the ever-changing market demands. Agile as a mindset and an approach to constant change is one technique organisations apply. This is supported by studies conducted by the World Economic Forum (2018), Balashova and Gromova (2017) and Fuchs and Hess (2018). This study found that Agile and innovation are two facets of organisational transformation.

The study propositions derived from the computed clusters firstly outline that Agile is one strategy organisations can adopt to respond and sustain innovation (P1). This is supported by Mills, Berthon and Pitt (2020), who suggested that effective innovation transformations within organisations are enabled by the need for constant change and adaptability, which represents the foundation of Agile. Mergel (2016) further purported that Agile as a mindset is the key to effective change management and adaptability. Therefore, if Agile supports the flexibility, adaptability and innovative efforts required to sustain organisations' transformation, then organisations should adopt Agile as a strategy for effective innovation-based organisational transformations. This proposition can be linked to the processes of innovation
TABLE 3: Cluster analysis findings.

\begin{tabular}{|c|c|c|}
\hline Cluster & Keywords in the cluster & $\begin{array}{l}\text { Study propositions } \\
\text { (Derived propositions 1-5) }\end{array}$ \\
\hline C1: Red & $\begin{array}{l}\text { Innovation } \\
\text { Strategy } \\
\text { Agility } \\
\text { Sustainability } \\
\text { Leadership } \\
\text { Simulation } \\
\text { Open innovation } \\
\text { Organisational agility } \\
\text { Flexibility }\end{array}$ & $\begin{array}{l}\text { Keyword analysis: } \\
\text { Assessing the keywords in } \mathrm{C} 1 \text { in the } \\
\text { order provided } \\
\text { The researcher can deduce the } \\
\text { following proposition: } \\
\text { P1: Innovation strategy is sustained by } \\
\text { Agility or Agility sustains innovation } \\
\text { strategies }\end{array}$ \\
\hline C2: Green & $\begin{array}{l}\text { Transformations } \\
\text { Agile methodology } \\
\text { Digital innovation } \\
\text { Digitisation } \\
\text { Collaboration } \\
\text { Competitive advantage }\end{array}$ & $\begin{array}{l}\text { Keyword analysis: } \\
\text { From the assessment of the } \mathrm{C} 2 \\
\text { keywords in, } \\
\text { - The keywords transformation and } \\
\text { digitisation form part of the digital } \\
\text { innovation. } \\
\text { With the remaining keywords, the } \\
\text { researcher can deduce the following } \\
\text { proposition: } \\
\text { P2 - Collaborating Agile methodology } \\
\text { with digital innovation leads to } \\
\text { Competitive advantage. }\end{array}$ \\
\hline C3: Yellow & $\begin{array}{l}\text { Agile development } \\
\text { Business model innovation } \\
\text { Industry } 4.0 \\
\text { Artificial intelligence } \\
\text { ( } 4.0 \text { driver) } \\
\text { Cloud computing ( } 4.0 \text { driver) } \\
\text { Acceleration } \\
\text { Internet of things ( } 4.0 \text { driver) } \\
\text { Machine learning ( } 4.0 \text { driver) } \\
\text { Facilitation }\end{array}$ & $\begin{array}{l}\text { Keyword analysis: } \\
\text { - There are Industry } 4.0 \text { and its driver } \\
\text { technologies - Five keywords in the } \\
\text { cluster all fall under this } 4.0 \text { theory } \\
\text { - The other keywords such as } \\
\text { acceleration and facilitation can be } \\
\text { integrated to form a proposition below. } \\
\text { Based on the analysis above, possible } \\
\text { propositions for C } 4 \text { can be: } \\
\text { P3: Agile development accelerates or } \\
\text { facilitates new business models, such as } \\
\text { Industry } 4.0\end{array}$ \\
\hline C4: Blue & $\begin{array}{l}\text { Design thinking, } \\
\text { Project management (PM) } \\
\text { Innovation management (IM) } \\
\text { Value creation } \\
\text { New product development } \\
\text { Agile software development } \\
\text { Agile approach application } \\
\text { Effectiveness }\end{array}$ & $\begin{array}{l}\text { Keyword analysis: } \\
\text { - Keywords, PM encompasses the } \\
\text { keywords, Agile software } \\
\text { development, Agile approach } \\
\text { application } \\
\text { - New product development forms part } \\
\text { of IM } \\
\text { - Design Thinking forms part of Agile } \\
\text { approach application } \\
\text { Therefore, based on the analysis above, } \\
\text { researcher can deduce the following } \\
\text { proposition: } \\
\text { P4: Design thinking as a concept of } \\
\text { project management creates value for } \\
\text { innovation management or } \\
\text { development of a new product }\end{array}$ \\
\hline C5: Purple & $\begin{array}{l}\text { Agile } \\
\text { Lean } \\
\text { Management } \\
\text { Conceptualisation } \\
\text { Theory } \\
\text { Prototyping }\end{array}$ & $\begin{array}{l}\text { Keyword analysis: } \\
\text { - From the first three keywords Agile, } \\
\text { lean, management, the researcher } \\
\text { deduces this to: Lean is an Agile } \\
\text { management theory } \\
\text { - Supporting the above theory with the } \\
\text { remaining keywords, which are } \\
\text { conceptualisation, theory, prototype, } \\
\text { allows the researcher to deduce the } \\
\text { proposition: } \\
\text { P5: This cluster presents the concept or } \\
\text { theory of lean Agile management }\end{array}$ \\
\hline
\end{tabular}

management model illustrated in the literature review specifically on Process one, which is on innovation management strategy because P1 suggests that Agility sustains innovation strategy. Agile falls as one strategy for innovation management.

The second proposition (P2) links the adoption of Agile as a methodology for transformation and digital innovations to facilitate organisation competitive advantage. According to Kayikci (2018), the continuous world digital transformation is a major critical urgency that organisations are constantly forced to adjust and respond to effectively. Effective response to this transformation has been through implementation of sustainable, continuous, innovative technology initiatives. According to Rigby et al. (2016), 
innovation means bringing good concepts into reality, continuously and successfully, to support organisation competitive advantage. Agile's nature of flexibility and adaptability to the constant changing market demands has fostered and supported technology innovations in organisations over the past decade (Mills et al. 2020). This proposition can be linked to the processes of innovation management model illustrated in the literature review specifically on Process 2, which is on systematic promotion of innovations to respond to change. P2 suggests that collaborating Agile methodology with digital innovation leads to competitive advantage. From the literature (Mills et al. 2020) and this study finding specifically based on Proposition two, Agile allows organisations continual response to change and transformation through its flexibility towards innovation that supports change and transformation. This leads to attainment of organisational competitive advantage. Hence, Process 2 of the innovation management model and the study $\mathrm{P} 2$ align.

The third proposition (P3), which is based on Cluster 3 (C3), is that Agile development accelerates or facilitates new business models, such as Industry 4.0 business models. According to Fuchs and Hess (2018), Agile supports digital transformations effectively. They base this on confirmation that successful digital transformations take place through adaptable and continuous innovations that result in radical change in business models and capabilities in existing processes. Agile enables organisations to work towards response and delivery of new developed ways, processes or techniques to respond to the changes in business models and capabilities in existing processes. This proposition can be linked to the processes of innovation management model illustrated in the literature review specifically on Process 3, which is on management of identified innovation processes. P3 suggests that Agile development accelerates or facilitates new business models, such as Industry 4.0 fuelled business models. The existing literature, such as a study by Kayikci (2018), states that Agile supports continuous response to change in business demands, which makes the methodology most suitable to respond to any new business demands including transformation based business model such as new industry 4.0 driven business models. This facilitates required organisations' flexibility to keep with the demands of modern business markets. Hence, Process three of the innovation management model and the study P3 collaborate.

The fourth proposition, $\mathrm{P} 4$, based on $\mathrm{C} 4$, suggests that design thinking as a concept of project management creates value for innovation management or development of a new product. This proposition is in line with Lukasik and Saylor (2018), who concluded that design thinking is an approach to managing projects that is most empathetic to the needs of users, by putting their needs at the centre of projects. This approach asks questions related to user-specific problems that need to be solved, with a focus on creating fresh innovative ideas that teams can test alongside a series of user-focussed exercises (Andrews 2019). With design thinking, the goal is for the team to be as innovative as possible to be able to develop a solution that meets users' actual needs. The application of design thinking as an approach for managing projects, therefore, facilitates effective innovation efforts in organisations.

Lastly, the fifth proposition, P5, based on C5, recognises the concept and theory of lean Agile management as the meaning behind C5. Lean Agile management is a mindset and approach to management that combines Agile beliefs, attributes, principles and lean thinking approaches (Schneider 2017). The lean Agile process integrates elements of both continuous delivery and optimised, constant improvement across the entire organisation value stream (Howard 2010). According to Kumar and Shankar (2016), Agile and lean co-exist to overcome the drawbacks of each other. This proposition can be linked to the processes of innovation management model illustrated in the literature review specifically on Process four, which is on effective management of change in processes. P5 is based on the concept or theory of lean Agile management. The current literature including studies by (Schneider 2017) and Kumar and Shankar (2016) stated that the Lean-Agile process combines elements from both continuous delivery and continual improvement, streamlined across the entire value chain. The concept aims to improve procedures that help Agile teams and organisations achieve their objective of delivering value often and iteratively (Howard 2010). Therefore, Process five of the innovation management model and the study P5 align.

The main aim of this study was to determine the relationship between Agile and innovation. The interdependency between Agile and innovation was identified, which is addressed through the strong link strength between Agile-based keywords and the keyword 'innovation'. Furthermore, the nature of this dependency has been established and illustrated through the profiling of clusters that led to Propositions 1-5. From this finding, the study has determined the link between Agile and innovation and, most importantly, has shown the concepts that represent Agile and innovation within organisations.

The general summary of the findings supported by the established propositions is that Agile and agility mindset should play a major role in proper innovation management. Agile drives change, and effective change management depends on Agile; furthermore, Agile's advocacy for value creation and constant collaborations facilitates innovative transformations and sustaining of new business models that are supported through technology.

The findings above highlight the following points:

- The Agile mindset is a factor needed to facilitate the innovation process within organisations. This is supported by Cluster one results. These results are in line with what Rigby et al. (2016) found, namely that the major aim of adopting Agile by organisations should be to improve innovation across all functions of the business. 
- Sustainable and effective innovation efforts and initiatives within organisations should be supported by the Agile mindset. This is supported by Cluster two results. This cluster implies that the Agile methodology facilitates digital innovations and transformations.

- The changing times that are driven mostly by constant innovative technologies are forcing organisations to change their inherent general models and way of thinking, and Agile as a mindset should be at the forefront in facilitating adequate adoption of this. This finding is based on the Cluster three proposition, which states that Agile drives and sustains new business models, for example, Industry 4.0. The changing global market demands require change in business models; Agile as indicated in P3 can facilitate this required transition.

\section{Conclusion and future research recommendation}

From the literature reviewed, it was concluded that there is a critical need for techniques that facilitate organisations' ability to respond effectively to the global transformation brought about by technology and globalisation. Innovation was identified as one process organisations can implement to respond to this. On the other hand, Agile as a rising global approach to effective change adoption has provided one way that organisations can use to respond to global transformation. This study mapped and established a link and interdependency between the concepts of Agile and innovation. Organisations need to acknowledge this interdependency because innovative efforts are only possible through adequate adaptation to change, which is what the Agile approach advocates. Likewise, the effective adoption of Agile can only be accomplished through continuous management of innovative efforts within organisations. This finding is in line with that of the World Economic Forum study (2018), which emphasises that organisations' innovation strategy must be developed with an agility mindset in place, as this is the key to their success.

A proper balance of these facts would facilitate efficient and effective management in the organisation innovation management strategy. Organisations must acknowledge that Agile adoption can facilitate the effectiveness of their innovative efforts. Agile should also be a mindset that is adopted in order to curb the problem of continuing market demands and technology transformation. Application of this solution would assist in the organisations' overall ability to manage change, implement the necessary innovative efforts as well as gain the financial benefits associated with the process.

The study solution indicates how imperative it is for organisations to realise Agile and innovation as two facets to facilitate organisation transformation. The future recommendations associated with this study could be explored further regarding the influence Agile adoption can have on innovation management specific to each sector or industry. This would create a clear path to the benefits of linking these two concepts for that specific industry.
Identifying what agility and innovation mean within the context of an industry would help pinpoint the exact path organisations can take to respond to global transformation.

\section{Acknowledgements Competing interests}

The authors affirm that they have no conflicting interests or relationships that may have improperly influenced them in writing this article.

\section{Authors' contributions}

M.T. conducted the conceptualisation, review of the literature and drafting of the article. C.M. was responsible for the article and quality reviews.

\section{Ethical considerations}

This article followed all ethical standards for research without direct contact with human or animal subjects.

\section{Funding information}

This research received no specific grant from any funding agency in the public, commercial or not-for-profit sectors.

\section{Data availability}

Data sharing is not applicable to this article as no new data were created or analysed in this study.

\section{Disclaimer}

The views and opinions expressed in this article are those of the authors and do not necessarily reflect the official policy or position of any affiliated agency of the authors.

\section{References}

Agostini, L. \& Filippini, R., 2019, 'Organizational and managerial challenges in the path toward Industry 4.0', European Journal of Innovation Management 22(3), 406-421. https://doi.org/10.1108/EJIM-02-2018-0030

Andrews, A., 2019, Design thinking (April), viewed 08 June 2020, from www.hbr.org.

Bahron, H., 2018, 'Research frontiers and way forward', IOP Conference Series: Earth and Environmental Science 117, 012049. IOP Publishing, Selangor, November 8-9, 2017.

Balashova, E.S. \& Gromova, E.A., 2017, 'Agile transformation of the Russian sector of economy according to the legislative framework', Journal of Advanced Research in Law and Economics 8(3), 749-753.

Beck, K. \& Beedle, M., 2001, 'Manifesto For Agile software development [online]', Agilemanifesto.org, viewed 01 September 2020, from http://agilemanifesto.org.

Caruso, L., 2018, 'Digital innovation and the fourth industrial revolution: Epochal social changes?', Al and Society 33(3), 379-392. https://doi.org/10.1007/s00146017-0736-1

De Brún, A. \& McAuliffe, E., 2018, 'Social network analysis as a methodological approach to explore health systems: A case study exploring support among senior managers/executives in a hospital network', International Journal of Environmental Research and Public Health 15(3), 1-11. https://doi.org/10.3390/ijerph15030511

Elsevier, 2019, About Scopus - Abstract and citation database, viewed 19 August 2020, from https://www.elsevier.com/solutions/scopus.

Fuchs, C. \& Hess, T., 2018, 'Becoming agile in the digital transformation: The process of a large-scale agile transformation', in International conference on information systems 2018, ICIS 2018, AIS eLibrary, San Francisco, CA, December 2018.

Horth, D. \& Buchner, D., 2014, Innovation leadership: How to use innovation to lead effectively, work collaboratively and drive results, p. 20, Center for Creative Leadership, Greensboro. 
Howard, R., 2010, 'Lean - Agile software development \& colon: Achieving enterprise agility,' Kybernete 39(5), 844-845. https://doi.org/10.1108/03684921011043314

IOWA State University Library, 2018, 'Scopus vs. web of science vs. google scholar', IOWA State University, pp. 9-11, viewed 08 June 2020, from http://instr.iastate. libguides.com/c.php?g=120420\&p=785310.

Kayikci, Y., 2018, 'Sustainability impact of digitization in logistics', in Procedia manufacturing, pp. 782-789.

Khalil, M.A. \& Kotaiah, B., 2018, 'Implementation of agile methodology based on SCRUM tool', in International Conference on Energy, Communication, Dato Analytics and Soft Computing (ICECDS), IEEE, Chennai, pp. 2351-2357.

Kogabayev, T. \& Maziliauskas, A., 2017, 'The definition and classification of innovation', HOLISTICA - Journal of Business and Public Administration 8(1), 59-72. https:// doi.org/10.1515/hjbpa-2017-0005

Kohnová, L., Papula, J. \& Salajová, N., 2019, 'Internal factors supporting business and technological transformation in the context of industry 4.0', Business: Theory and Practice 20, 137-145. https://doi.org/10.3846/btp.2019.13

Krstić, M., Skorup, A. \& Lapčević, G., 2018, 'Trends in agile innovation management', International Review (3-4), 58-70. https://doi.org/10.5937/IntRev1804058K

Kumar, T.H. \& Shankar, C.U., 2016, 'Lean as Agile methodology - A study', International Journal of Advanced Networking and Applications 7(6), 2949-2952.

Lukasik, R. \& Saylor, J., 2018, 'Agile, meet design thinking: First impressions matter', ExpertInsights@IBV, IBM Institute for Business Value, viewed 04 September 2020 from https://www.ibm.com/downloads/cas/7KL6JLMJ.

Mbelli, T.M. \& Hira, J., 2016, 'The perceptions of Agile methodology in South Africa', in Computer Science \& Information Technology (CS \& IT): An open access-compute science conference proceedings (CSCP), Academy \& Industry Research Collaboration Center (AIRCC), Chennai, December 24-25, 2016, vol. 6, pp. 219-227.

Mergel, I., 2016, 'Agile innovation management in government: A research agenda', Government Information Quarterly 33(3), 516-523. https://doi.org/10.1016/j. giq.2016.07.004

Mills, A.J., Berthon, P.R. \& Pitt, C., 2020, 'Agile authorship: Evolving models of innovation for information-intensive offerings', Journal of Business Research 110 577-583. https://doi.org/10.1016/j.jbusres.2018.05.010

Morris, L., 2016, 'Agile innovation', in The innovation tools handbook: Organizational and operational tools, methods, and techniques that every innovator must know, John Wiley \& Sons, New Jersey.

Nambisan, S., lyytinen, K., Majchrzak, A. \& Song, M., 2017, 'Digital innovation management: Reinventing innovation management research in a digital world", MIS Quarterly 41(1),223-238. https://doi.org/10.25300/MISO/2017/41:1.03
O'Leary, J., Cota, R. \& Otis, G., 2017, 'Successful Agile in government: Supporting the product owner', Agile in government: A playbook from the Deloitte center for government insights, pp. 24-32, viewed from https://www2.deloitte.com/ content/dam/insights/us/articles/3897_Agile-in-government/DUP_Agile-incontent/dam/insights/

Rigby, D.K., Sutherland, J. \& Takeuchi, H., 2016, 'Embracing Agile - How to master the process that's transforming management', Harvard Business Review, viewed 04 September 2020, from https://hbr.org/2016/05/embracing-agile.

Rix, M., Kujat, B., Meisen, T. \& Jeschke, S., 2016, 'An Agile information processing framework for high pressure die casting applications in modern manufacturing systems', Procedia CIRP 41, 1084-1089. https://doi.org/10.1016/j.procir. 2015.12.134

Schneider, J., 2017, Understanding design thinking, lean and Agile, viewed 12 June 2020, from http://oreilly.com/safari.

Serrat, O., 2017, Knowledge solutions: Tools, methods, and approaches to drive organizational performance, Springer Nature, New York.

Siddaway, A., 2014, 'Guide for Conducting and Reporting Narrative Reviews, MetaAnalyses, and Meta-Syntheses', Annual Review of Psychology 70, 747-770.

Şimşit, Z.T., Vayvay, Ö. \& Öztürk, Ö., 2014, 'An outline of innovation management process: Building a framework for managers to implement innovation', Procedia - Social and Behavioral Science 150, 690-699. https://doi.org/10.1016/j. sbspro.2014.09.021

Thrassou, A., Vrontis, D. \& Bresciani, S., 2018, 'The Agile innovation pendulum: A strategic marketing multicultural model for family businesses', Internationa Studies of Management and Organization 48(1), 105-120. https://doi.org/10.108 $0 / 00208825.2018 .1407178$

Tokody, D., 2018, 'Digitising the European industry - Holonic systems approach', in Procedia Manufacturing, pp. 1015-1022.

Van Eck, N.J. \& Waltman, L., 2010, 'Software survey: VOSviewer, a computer program for bibliometric mapping', Scientometrics 84, 523-538. https://doi.org/10.1007/ s11192-009-0146-3

Wagner, T., Herrmann, C. \& Thiede, S., 2017, 'Industry 4.0 impacts on lean production systems', in Procedia CIRP, pp. 125-131.

World Economic Forum, 2018, 'White paper on Agile governance: Reimagining policymaking for the fourth industrial revolution', World Economic Forum (WEF) (January), p. 17, viewed from http://www3.weforum.org/docs/WEF_Agile Governance_Reimagining_Policy-making_4IR_report.pdf.

Yun, J., Jeong, E., Zhao, X., Hahm, S. \& Kim, K., 2019, 'Collective intelligence: An emerging world in open innovation', Sustainability 11(16), 4495. https://doi. org/10.3390/su11164495 